\title{
Assessment and Spatial Variability Mapping of Soil Available Phos- phorus and Potassium of Coarse-textured Soils in New Valley, Egypt Using Geostatistical Technique
}

\author{
Swify, Samar S.F. ${ }^{1}$;.H. Abd El-Aziz ${ }^{2}$; S.A.H. Selmy ${ }^{2}$; A. Elgharably ${ }^{2}$ and \\ H.M.A. Ragheb ${ }^{2}$
}

${ }^{1}$ Soils and Water Dept., Faculty of Agriculture, Assiut University, New Valley Branch, Egypt.

${ }^{2}$ Soils and Water Department, Faculty of Agriculture, Assiut University, Assiut, Egypt.

Received on: 10/9/2017

Accepted for publication on: 19/9/2017

\section{Abstract}

Assessment and understanding of soil available phosphorus (P) and potassium $(\mathrm{K})$ content distribution is an important part of deciding whether or not the fertilization is appropriate or even necessary for a soil. So, the main objective of this study is to evaluate and map the spatial variability of the available soil $\mathrm{P}$ and $\mathrm{K}$ using the geostatistical technique. Georeferencing surface soil samples (0-25 $\mathrm{cm})$ were collected from four sites representing course-textured soils in ElKharga and El-Dakhla oases. Ordinary Kriging (OK) technique was applied for the spatial interpolation of available soil $\mathrm{P}$ and $\mathrm{K}$ contents. The spatial distribution of available $\mathrm{P}$ and $\mathrm{K}$ was analyzed and mapped by Arc GIS (version 10.2.2). The results showed that concentrations of the available soil $\mathrm{P}$ and $\mathrm{K}$ ranged from 0.35 to $85.02 \mathrm{mg} / \mathrm{kg}$ and from 11 to $6204 \mathrm{mg} / \mathrm{kg}$, respectively. The nugget-to-sill ratio suggested a strong spatial dependence for both available soil $\mathrm{P}$ and $\mathrm{K}$ in all sites of the study area, indicating that the available soil $\mathrm{P}$ and $\mathrm{K}$ were mainly controlled by intrinsic factors. The interpolation models varied for both $\mathrm{P}$ and $\mathrm{K}$ as well as from site to another site across the study area. Cross-validation proved that the chosen models were the best fitted semivariogram models to map spatial distribution of the available soil $\mathrm{P}$ and $\mathrm{K}$. The produced maps of spatial distributions for soil $\mathrm{P}$ and $\mathrm{K}$ availability were characterized by high accuracy. So, site specific management can be planned and considered to be applied for this study area. Also, these maps can facilitate and help in making decisions for choose appropriate fertilization policies for these soils as well as to avoid adding fertilizers for sites which do not need to be fertilized. Our results confirmed that the integration of statistics, geostatistics and GIS provides a powerful tool to assess, describe and map the spatial variability of the available soil phosphorus and potassium. As well as to develop high resolution maps that may aid variable rate management (e.g. fertilization).

\section{Keywords: Mapping, Geostatistics, Phosphorus, Kriging, Potassium, GIS, New valley.}

\section{Introduction}

New Valley governorate is a part of the western desert and lies in the south-western part of Egypt. It covers an area of about 440,098 $\mathrm{km}^{2}$ and represents about $44 \%$ of the total area of Egypt. It includes three big oases namely El-Kharga,
El-Dakhla and El-Farafra. The main occupation for inhabitants in this governorate is agriculture. The climate of New Valley governorate is extremely arid with long hot and rainless weather in summer and mild with rare precipitation in winter. The groundwater is the only water re- 
source for all activities in these oases. New Valley governorate is considered one of most promising areas for the agricultural development in Egypt. So, it is important to quantify the variability in soil nutrient stocks of this area.

The soil phosphorus $(\mathrm{P})$ and potassium $(\mathrm{K})$ contents play an important role in plant growth and crop yield. They can limit or co-limit the plant growth (Tripler et al., 2006; Li et al., 2016). Human activities such as fertilization, reclamation and weeding have effects on biogeochemical cycling of $\mathrm{P}$ and $\mathrm{K}$. Thereby, it alters the pattern, magnitude and extent of nutrient limitation on land (Marklein and Houlton, 2012). Also, soil $P$ distribution is influenced by water movement, as dissolved $\mathrm{P}$ is carried by runoff and bound $\mathrm{P}$ can be associated with suspended sediment (Lin, et al., 2009; Elrashidi et al., 2012).

In most cases, soils in the same area are characterized by a highly spatial and temporal variability. So, the spatial distribution of soil nutrients under agricultural systems is affected by natural conditions of the soil formation such as parent material, topography, climate, biological activities and natural soil properties (Brady and Weil, 2000; Tang and Yang, 2006) as well as management practices (Huang, 2000; Barton et al., 2004; Atreya et al., 2008).

The geostatistical analysis is an important tool of accurately predicting soil nutrient distributions at different spatial scales. According to Goovaerts (1999), geostatistics is used to estimate and map soils in unsampled areas. It provides a means of interpolating values for points that are not physically sampled using knowledge about the underlying spatial relationships in a data set; it is based on regionalized variable theory of an optimal interpolation estimate for a given coordinate location; it provides high confidence in the interpolated values. The approach requires a fairly dense sampling network and thus incurs a relatively high cost (Wu et al., 2003; Sauer et al., 2006; Robertson, 2008; Fu et al., 2013, Liu et al., 2013).

Kriging is a group of estimators used to interpolate spatial data. It includes ordinary kriging, universal kriging, indicator kriging, cokriging and others. The choice of which kriging to be used depends on data characteristics and the type of spatial model desired. The most commonly used method is the ordinary kriging $(\mathrm{OK})$, which was selected for this study because of its simplicity and prediction accuracy in a comparison with other kriging methods (Isaaks and Srivastava, 1989). The ordinary kriging (OK) is a spatial estimation method where the error variance is minimized (Yamamoto, 2005). The main objective of this study is to determine and map the soil available contents of $\mathrm{P}$ and $\mathrm{K}$ and their spatial variability in the study area using the geostatistical technique.

\section{Materials and Methods}

\subsection{Study Area}

The study area involved four sites which were selected from ElKharga and El-Dakhla oases, New Valley, Egypt (Figure 1) to evaluate and map the spatial variability of the available $\mathrm{P}$ and $\mathrm{K}$ using geostatistical 
technique. Two sites were located in El-Kharga oasis (El- Mounira and Bolaq) and the other ones were found in El-Dakhla oasis (Zakhera and Mut). El- Monira site (A) is located between latitudes of

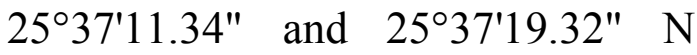
and longitudes of $30^{\circ} 38^{\prime} 21.66^{\prime \prime}$ and $30^{\circ} 38^{\prime} 40.02^{\prime \prime} \mathrm{E}$, while Bolaq site (B) is located between latitudes of $25^{\circ} 11^{\prime} 14.40^{\prime \prime}$ and $25^{\circ} 12^{\prime} 56.22^{\prime \prime} \mathrm{N}$ and longitudes of $30^{\circ} 31^{\prime} 9.18^{\prime \prime}$ and 30³2'8.52" E. Moreover, Zakhera site $(\mathrm{C})$ is situated between latitudes

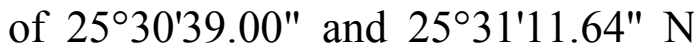
and longitudes of $29^{\circ} 16^{\prime} 50.04^{\prime \prime}$ and $29^{\circ} 17^{\prime} 56.58^{\prime \prime}$ E. In addition, Mut site (D) lies between latitudes of $25^{\circ} 25^{\prime} 39.24^{\prime \prime}$ and $25^{\circ} 26^{\prime} 59.34^{\prime \prime} \mathrm{N}$ and longitudes of $28^{\circ} 58^{\prime} 5.70^{\prime \prime}$ and 28०58'54.96" E.

2.2 Soil Sampling and Laboratory Analysis

Soil samples were collected from cultivated areas in the chosen sites in the first week of August 2015. Locations of these soil samples were recorded in the field by the Global Positioning System "Garmin GPS $\square$ and plotted on the location maps
(Figure 2). One hundred and thirtyseven soil samples $(50,25,30$ and 32 samples) were collected from sites A, $\mathrm{B}, \mathrm{C}$ and $\mathrm{D}$, respectively to represent the study area. The samples were collected from the surface layer (0-25 $\mathrm{cm})$ of the soil. They were taken using the systematically sampling grid within a distance between two consequent samples of $200 \mathrm{~m}$ in sites A, B and $\mathrm{C}$ and $50 \mathrm{~m}$ in site $\mathrm{D}$.

The collected soil samples were air-dried, crushed, sieved through a 2-mm sieve and then analyzed. Some physical and chemical properties of these soil samples (soil texture, SP, pH, ECe, OM and $\mathrm{CaCO}_{3}$ ) were determined according to Jackson (1973) and Page et al., (1984), (Table 1). The available soil phosphorus $(\mathrm{P})$ was extracted by 0.5 $\mathrm{M} \mathrm{NaHCO} 3$ at $\mathrm{pH} 8.5$ (Olsen et al., 1954) and determined using spectrophotometer at wavelength $660 \mathrm{~nm}$. The available potassium (K) was extracted from the soil samples by $1 \mathrm{M}$ ammonium acetate at $\mathrm{pH} 7.0$ (Jackson, 1973) and then measured using the flame photometer. 


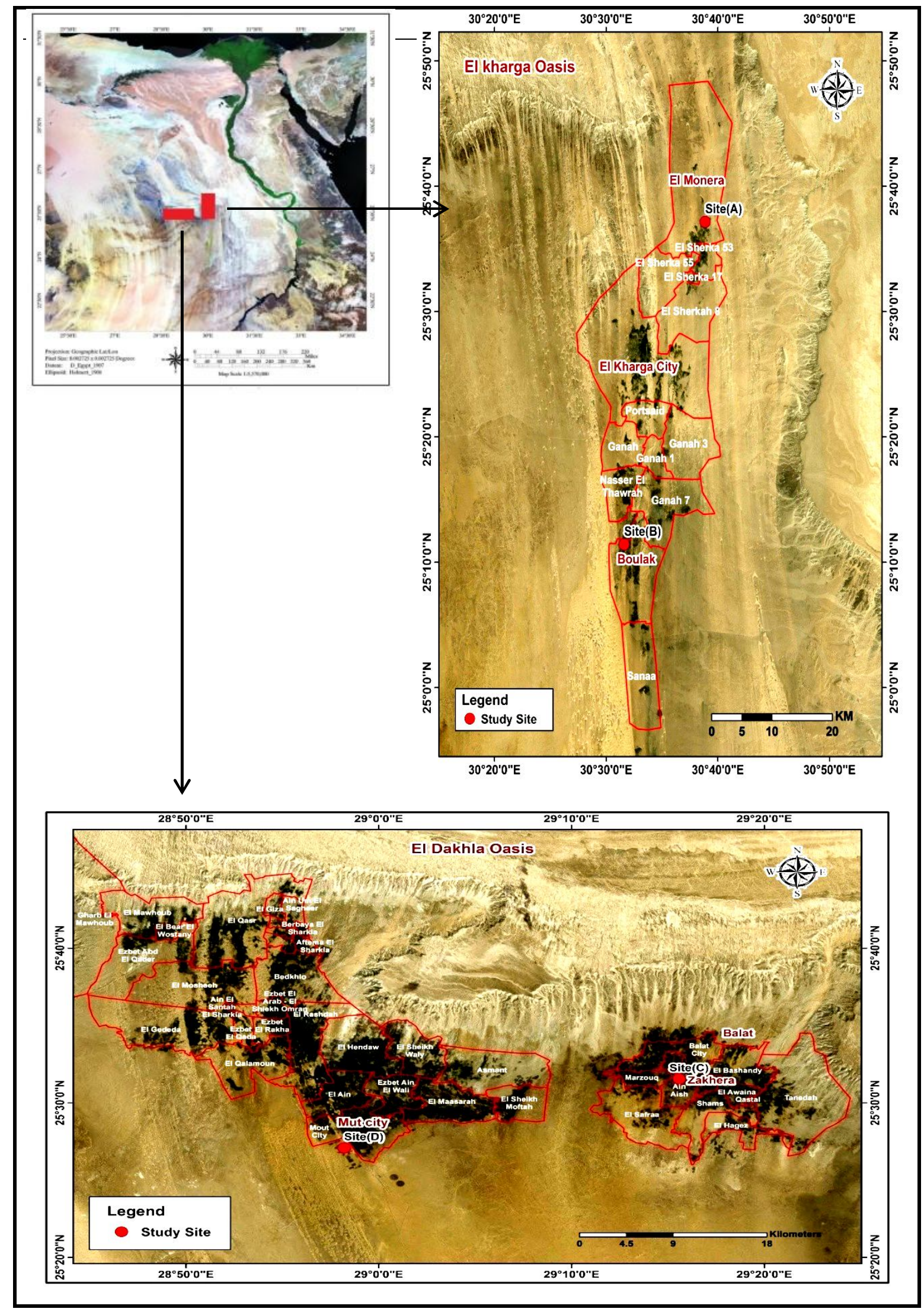

Figure (1): The location map of the study area. 


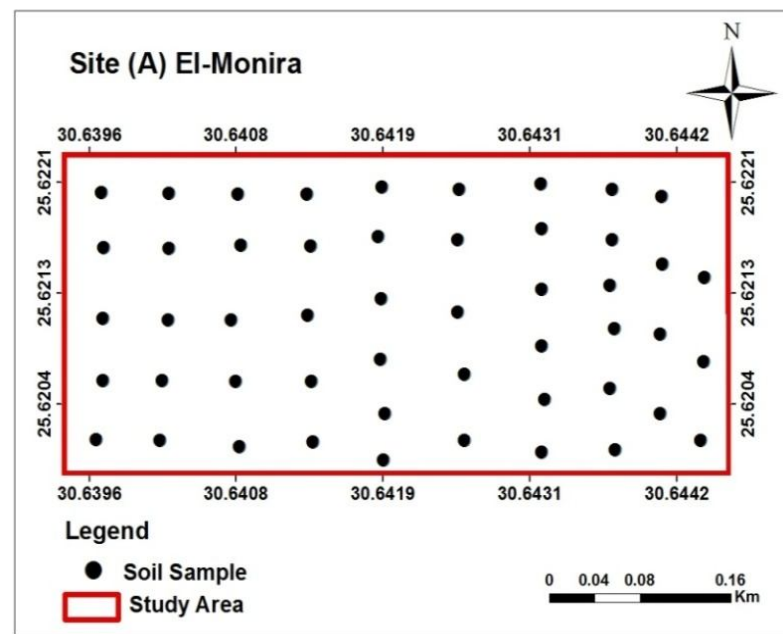

Study Sites
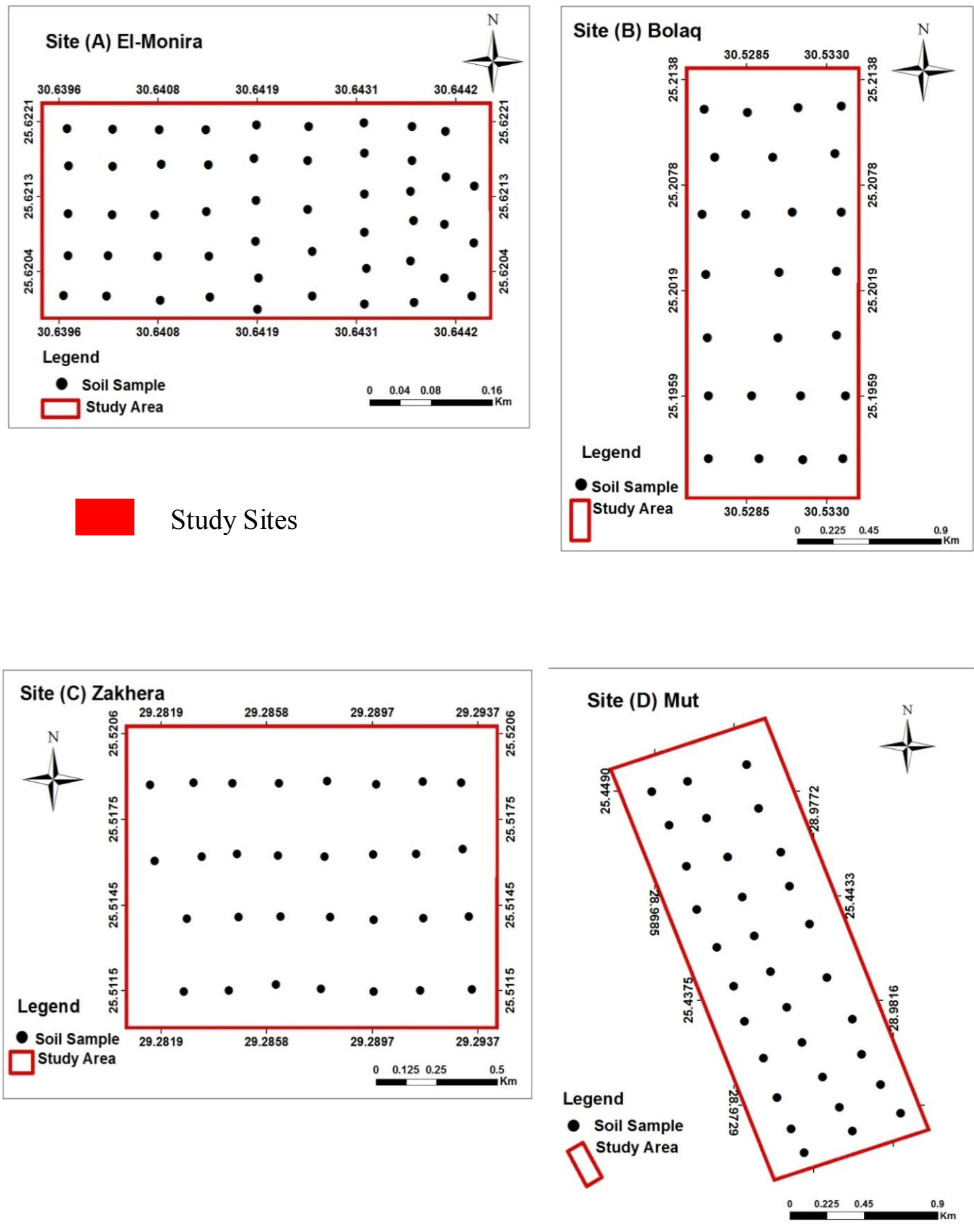

Figure (2): Locations of the soil samples collected from sites A, B, C and D. 
Table 1. Descriptive statistics of some soil properties and soil texture of the study sites.

\begin{tabular}{|c|c|c|c|c|c|}
\hline property & Site & Minimum & Maximum & Mean & SD \\
\hline SP (\%) & $\mathrm{A}$ & 34.3 & 40.8 & 37.7 & 1.7 \\
\hline & $\mathrm{B}$ & 15.8 & 27.0 & 20.0 & 3.1 \\
\hline & $\mathrm{C}$ & 17.9 & 42.5 & 31.9 & 7.7 \\
\hline & $\mathrm{D}$ & 18.0 & 36.9 & 24.7 & 5.4 \\
\hline pH (1:1) & $\mathrm{A}$ & 7.6 & 8.2 & 7.9 & 0.2 \\
\hline & $\mathrm{B}$ & 7.9 & 9.1 & 8.5 & 0.3 \\
\hline & $\mathrm{C}$ & 7.2 & 8.7 & 8.0 & 0.4 \\
\hline & $\mathrm{D}$ & 7.6 & 9.1 & 8.5 & 0.3 \\
\hline $\operatorname{ECe}\left(\mathrm{dSm}^{-1}\right)$ & $\mathrm{A}$ & 2.7 & 19.0 & 9.3 & 4.9 \\
\hline & B & 1.3 & 29.3 & 4.9 & 8.4 \\
\hline & $\mathrm{C}$ & 1.6 & 64.5 & 8.7 & 14.1 \\
\hline & $\mathrm{D}$ & 0.6 & 34.7 & 8.4 & 6.7 \\
\hline $\mathrm{CaCO}_{3}(\%)$ & $\mathrm{A}$ & 8.7 & 20.4 & 14.7 & 3.7 \\
\hline & $\mathrm{B}$ & 2.6 & 41.2 & 21.4 & 8.5 \\
\hline & $\mathrm{C}$ & 2.2 & 66.0 & 18.0 & 14.1 \\
\hline & $\mathrm{D}$ & 0.9 & 79.9 & 26.9 & 16.5 \\
\hline OM (\%) & $\mathrm{A}$ & 0.10 & 0.82 & 0.42 & 0.2 \\
\hline & B & 0.10 & 0.88 & 0.25 & 0.2 \\
\hline & $\mathrm{C}$ & 0.00 & 0.73 & 0.27 & 0.2 \\
\hline & $\mathrm{D}$ & 0.00 & 0.94 & 0.36 & 0.3 \\
\hline Texture & A & \multicolumn{4}{|c|}{ Sandy loam } \\
\hline & $\mathrm{B}$ & \multicolumn{4}{|c|}{ Sand, Loamy sand } \\
\hline & $\mathrm{C}$ & \multicolumn{4}{|c|}{ Sand, Loamy sand, Sandy loam } \\
\hline & $\mathrm{D}$ & \multicolumn{4}{|c|}{ Sand, Loamy sand, Sandy loam } \\
\hline
\end{tabular}

$\mathrm{SP}=$ Saturation Percentage, $\mathrm{SD}=$ Standard Deviation.

\subsection{Statistical and Geostatistical Analyses}

The statistical analysis including minimum, maximum, range, mean, standard deviation, coefficient of variation, skewness and kurtosis, which are generally accepted as indicators of the central tendency, were estimated by using SAS software version 11. Geostatistical analyses and the distribution maps of the available soil $\mathrm{P}$ and $\mathrm{K}$ contents were produced by ArcGIS (10.2.2).

Geostatistical analysis first to fully explored the data in which the histogram, normality, trend of data, semivariogram cloud and cross covariance cloud of the raw data were observed (Sarangi et al., 2005). In ArcGIS geostatistical analyst, the histogram and normal QQPlots tools were used to see what transformations were needed to make the data more normally distributed. Histogram and normal QQPlots analysis were applied for both available $\mathrm{P}$ and $\mathrm{K}$ of the investigated soil samples to check its data to see if it have normal distribution or not. Logarithmic transformation had been used for $\mathrm{P}$ and $\mathrm{K}$ content data to normalize too highly skewed and outlier data sets because kriging methods work best if the data is approximately normally distributed (Johnston et al., 2001). The semivariogram models were chosen 
from a set of mathematical functions that describe spatial relationships and usually fitted by weighted lost squares, range, nugget and sill and then used in the spatial interpolation method of kriging (Krige, 1951; Matheron, 1971). Ordinary Kriging (OK) method was used in the present study as interpolation method because it is simple and has high accuracy for prediction in comparison to other kriging methods.

According to Journel and Huijbregts (1978), the semivariance function $\gamma(h)$ was computed as the half of the expected squared difference between values at locations separated by a given lag and was used to express spatial variations.

Semivariograms were calculated using the following equations 1 and 2 : $\gamma(h)=\frac{1}{2 N(h)} \sum_{i=1}^{N(h)}\left[Z\left(x_{i}+h\right)-Z\left(x_{i}\right)\right]^{2}$

Where: $N(h)$ is the number of sample pairs points that are located by a particular distance $(h)$ from each other; $\mathrm{Z}(x i)$ and $\mathrm{Z}(x i+h)$ are the values of regionalized variable at location $x i$ and $(x i+h)$, respectively.
$\mathrm{Z}^{*}\left(\mathrm{X}_{0}\right)=\sum_{i=1}^{N} \lambda_{\mathrm{i}} \mathrm{Z}\left(\mathrm{X}_{\mathrm{i}}\right)$ with $\sum_{i=1}^{N} \lambda_{i}=1$

Where, $\mathrm{Z}^{*}(\mathrm{Xo})$ is the estimated variable at $\mathrm{Xo}$ location, $\mathrm{Z}^{*}(\mathrm{Xo})$ is values of investigated variable at $\mathrm{Xi}$ location and $\lambda \mathrm{i}$ is the statistical weight that is given to $\mathrm{Z}(\mathrm{Xi})$ sample located near Xo. $N$ is the number of observations in the neighborhood of estimated point. Accuracy assessment of interpolation was done by using Cross-validation methods (Goovaerts, 1999).

In this study, spatial parameters such as nugget, sill and range were calculated by using the semivariogram model, which provides information about the structure as well as the input parameters for the kriging interpolation. Nugget $\left(\mathrm{C}_{0}\right)$ is the variance at zero distance, sill $\left(\mathrm{C}+\mathrm{C}_{0}\right)$ is the lag distance between measurements at which one value for a variable does not influence neighboring values and range (a) is the distance at which values for one variable becomes spatially dependent of another (Figure 3).

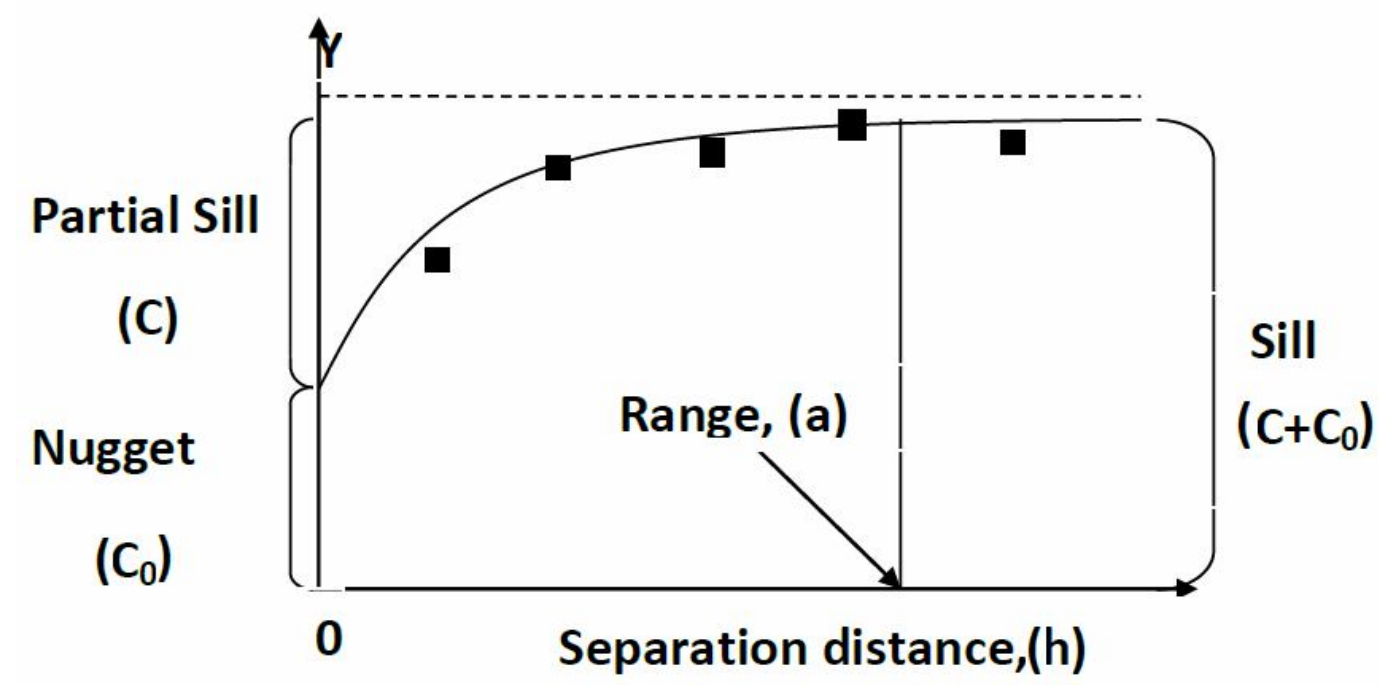

Figure (3): A variogram illustrating the relationship between variogram parameters (nugget, partial sill, and sill) and sample separation distance. 
Eleven semivariogram models (circular, spherical, tetraspherical, pentaspherical, exponential, gaussian, rational quadratic, hole effect, kbessel, j-bessel and stable) were tested for both available soil $\mathrm{P}$ and $\mathrm{K}$ in all study sites data set. Prediction performances were assessed by cross validation, which examines the accuracy of the generated surfaces. For a model that provides accurate predictions, the standardized mean error (MSE) should be close to zero, the root-mean-square error (RMSE) and average standard error (ASE) should be as small as possible (useful when comparing models), and the root mean square standardized error (RMSS) should be close to one (Johnston et al., 2001).

\section{Results and Discussion}

\subsection{Descriptive Statistics}

The descriptive statistics showed considerable variations in soil contents of available phosphorus and potassium in all studied sites as shown in Table (2). The data revealed that the available $\mathrm{P}$ soil content varied in the range of 4.4 to $85.0 \mathrm{mg} / \mathrm{kg}$ with mean of $18.6 \mathrm{mg} / \mathrm{kg}$, from 2.2 to $41.0 \mathrm{mg} / \mathrm{kg}$ with mean of $16.8 \mathrm{mg} / \mathrm{kg}$, from 0.4 to $25.5 \mathrm{mg} / \mathrm{kg}$ with mean of
$6.1 \mathrm{mg} / \mathrm{kg}$ and from 5.5 to 29.6 $\mathrm{mg} / \mathrm{kg}$ with mean of $16.4 \mathrm{mg} / \mathrm{kg}$, in these respective sites $\mathrm{A}, \mathrm{B}, \mathrm{C}$ and $\mathrm{D}$, respectively. While, the soil available $\mathrm{K}$ ranged from 52 to 1883 with mean of 359 , from 217 to 6204 with mean 1050, from 268 to 1986 with mean of 721 and from 11 to 762 with mean of $168 \mathrm{mg} / \mathrm{kg}$ in the studied sites A, B, $\mathrm{C}$ and $\mathrm{D}$. The available soil phosphorus and potassium of the studied soils have very high differences between their minimum and maximum values, which indicate that they have a lack of homogeneous distribution in all studied sites (Table 2).

The standard deviation (SD) is a measure that is used to quantify the amount of variation or dispersion of a set of data values. In this study, the results showed that the standard deviation (SD) values for the available soil $\mathrm{P}$ ranged from 4.6 to $13.2 \mathrm{mg} / \mathrm{kg}$ and varied from 170.5 to 1357.9 $\mathrm{mg} / \mathrm{kg}$ for the available soil $\mathrm{K}$. A low standard deviation indicates that the data points tend to be close to the mean of the set, while a high standard deviation means that the data points are spread out over a wide range of values.

Table 2. Descriptive statistics of available soil phosphorus $(\mathrm{P})$ and potassium $(\mathrm{K})$ of the study sites.

\begin{tabular}{|c|c|c|c|c|c|c|c|c|}
\hline Nutrient & Site & Min. & Max. & Mean & SD & CV (\%) & Kurtosis & Skewness \\
\hline P $(\mathrm{mg} / \mathrm{kg})$ & A & 4.4 & 85.0 & 18.6 & 13.2 & 70.9 & 12.5 & 2.9 \\
\hline & B & 2.2 & 41.0 & 16.8 & 9.0 & 53.4 & 1.2 & 0.9 \\
\hline & C & 0.4 & 25.5 & 6.1 & 4.6 & 76.5 & 10.3 & 2.6 \\
\hline & D & 5.5 & 29.6 & 16.4 & 6.1 & 37.3 & -0.3 & 0.6 \\
\hline K $(\mathrm{mg} / \mathrm{kg})$ & A & 52 & 1883 & 359 & 290.2 & 80.8 & 14.8 & 3.1 \\
\hline & B & 217 & 6204 & 1050 & 1357.9 & 129.4 & 9.9 & 3.1 \\
\hline & C & 268 & 1986 & 721 & 280.4 & 38.9 & 14.6 & 3.2 \\
\hline & D & 11 & 762 & 168 & 170.5 & 101.6 & 4.1 & 2.0 \\
\hline
\end{tabular}

$\mathrm{SD}=$ Standard Deviation; $\mathrm{CV}=$ Coefficient of Variance 
The coefficient of variation (CV) is a useful statistic for comparing the degree of variation from one data series to another, even if the means are drastically different from one to another. The coefficient of variation $(\mathrm{CV})$ that is less than $10 \%$ indicates a low variability, $10 \%-90 \%$ has a moderate variability, and $\mathrm{CV}$ greater than $90 \%$ shows high variability (Fang et al., 2012). In this study, the $\mathrm{CV}$ of the available soil $\mathrm{P}$ varied from 37.3 to $76.5 \%$ which indicated that the studied soil samples had moderate variability of the available $\mathrm{P}$ in all studied sites. However, the available soil $\mathrm{K}$ had a moderate to a high variability where the $\mathrm{CV}$ values ranged between 38.9 and $129.4 \%$ among all the study sites. On the other hand, the moderate variability of the available soil $\mathrm{K}$ occurred in the studied soil samples of sites A and C, while the high variability was found in soils of sites B and D. The moderate and high variability of the available soil $\mathrm{P}$ and $\mathrm{K}$ may be due to the human activities and natural conditions such as agricultural management practices and soil characteristics.

Skewness is a term in statistics used to describe the asymmetry from the normal distribution in a set of statistical data. Skewness can come in the form of a negative or positive value, depending on whether data points are skewed to the left, negative, or to the right, positive of the data average. A data set that shows this characteristic differs from a normal bell curve. The data of the available soil $\mathrm{P}$ and $\mathrm{K}$ contents of this study were skewed and needed to transform to be close to the normal distribution. The skewness values were positive and ranged between 0.6 and 2.9 for the available soil $\mathrm{P}$ content and between 2.0 and 3.2 for the available soil K content. Similar to skewness, kurtosis is a descriptor of the shape of a probability distribution. All values of kurtosis were positive except the value for the available soil $\mathrm{P}$ in site $\mathrm{D}$ which was negative (Table 2). It ranged between -0.3 and 12.5 for soil $\mathrm{P}$ content, while the kurtosis value of the available soil $\mathrm{K}$ varied from 4.1 to 14.9. Estimating both skewness and kurtosis values, the data of the available soil $\mathrm{P}$ and $\mathrm{K}$ needed to be normally distributed by using the geostatistical analysis. Therefore, a log-transformation was applied.

3.2 Availability Assessment of Soil $P$ and $K$ in the Studied Sites

According to Horneck et al., (2011), the $\mathrm{P}$ and $\mathrm{K}$ availability in soils can be classified as shown in Table (3). Generally, according to this classification, that these soils have a moderate soil available $\mathrm{P}$ content in all sites except site $\mathrm{C}$ which has a low available soil P. Moreover, these soils have moderate, high and very high available $\mathrm{K}$ levels in sites $\mathrm{D}, \mathrm{A}, \mathrm{C}$ and $\mathrm{B}$, respectively. Based on the mean available $P$ and $K$ values (Table 2), the studied sites were in the order of $\mathrm{A}>\mathrm{B}>\mathrm{D}>\mathrm{C}$ in their richness in the available soil $P$, while they were in the order of $\mathrm{B}>\mathrm{C}>\mathrm{A}>$ $\mathrm{D}$ in their contents of available soil $\mathrm{K}$.

The high values of soil available $\mathrm{P}$ and $\mathrm{K}$ contents of these soils may be related to the high $\mathrm{P}$ and $\mathrm{K}$ fertilization rates and to the soil parent material richness in some sources of 
them such as phosphate rock and shale, as well as the low leaching processes in the studied sites. Site (A) has the highest availability of the soil $\mathrm{P}$ because the soils of this site have more suitable properties such as low $\mathrm{CaCO} 3$ and $\mathrm{pH}$, high $\mathrm{SP}$ and $\mathrm{OM}$, as well as suitable texture for $\mathrm{P}$ availability than other sites (Table 1).

Table 3. Classification of $P$ and $K$ availability in soils.

\begin{tabular}{|c|c|c|c|c|}
\hline \multicolumn{5}{|c|}{ Classification } \\
\hline & Low & Moderate & High & Very high \\
\hline $\mathbf{P ~ ( m g / k g )}$ & $<10$ & $10-25$ & $25-50$ & $>50$ \\
\hline $\mathbf{K ~ ( m g / k g ) ~}$ & $<150$ & $150-250$ & $250-800$ & $>800$ \\
\hline
\end{tabular}

(Adopter from Horneck et al., 2011)

3.3. Geostatistical Analyses of Available Soil $P$ and $K$ Contents.

\subsubsection{Exploratory statistics} and data analysis

Available soil $\mathrm{P}$ and $\mathrm{K}$ in all study sites were checked by histogram and normal QQPlots to see if they show a normal distribution pattern or not. Normal QQPlots provide an indication of unvaried normality. If the data are asymmetric (i.e., far from normal), the points will deviate from the line. According to the QQPlots and histogram analysis, it was clear that both available soil phosphorus and potassium contents deviated from the normal distribution except the available soil $\mathrm{P}$ in site $\mathrm{B}$ which showed a normal distribution. Therefore, a log-transformation was carried out to the data of all sites to normalize their distribution except data of site $B$ in case the available $P$.
Figure (4) showed some examples of the normal QQPlots and the histogram analysis for the available soil $\mathrm{P}$ and $\mathrm{K}$ data. The histogram illustrated a unimodle shape for the original data of the available soil $\mathrm{P}$ in site $\mathrm{B}$ and logarithmic transformed data of the other sites for both available $\mathrm{P}$ and $\mathrm{K}$. By the same way QQPlots showed that the points were approximately on the line for the original data of the available soil $\mathrm{P}$ in site $B$ but logarithmic transformed data were done the other sites. The skewness values which close to zero and kurtosis values which close to 3.0 indicated that the original data of the available soil $P$ in site $B$ and logarithmic transformed data of the other sites did not deviate from the normal distribution (Figure 4). 

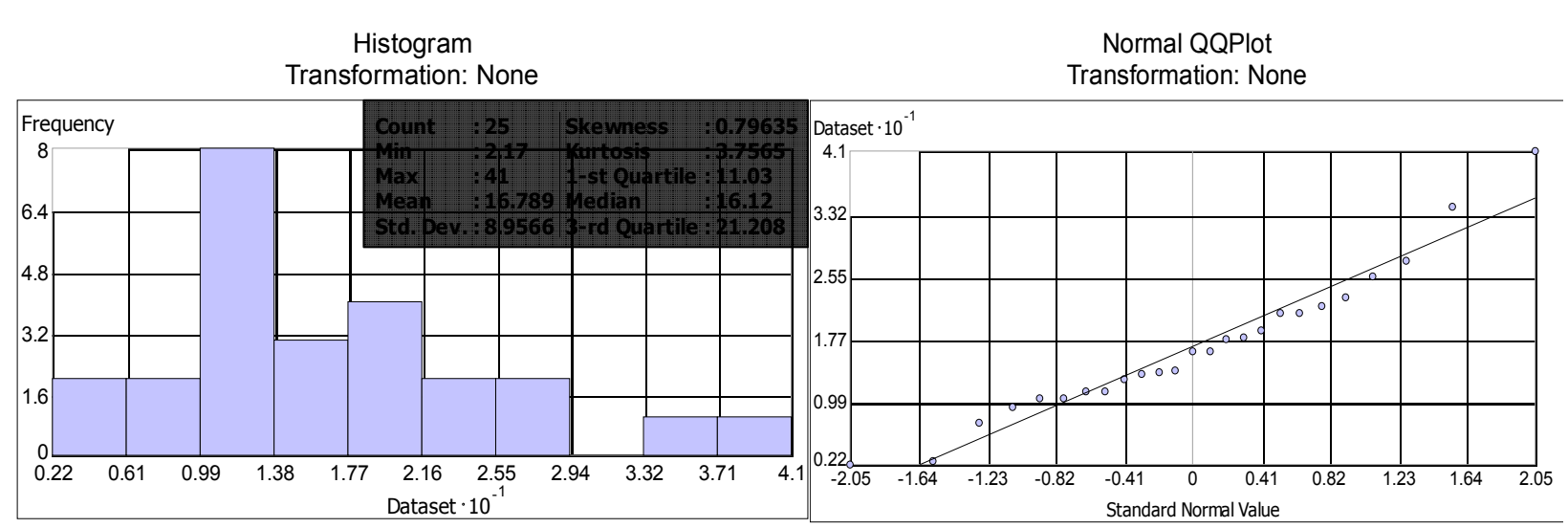

Dataset : point_3 Attribute: availabl_1

Dataset : point_3 Attribute: availabl_1

Original data of the available soil $\mathrm{P}$ in site $\mathrm{B}$ as an example of normally distributed data.
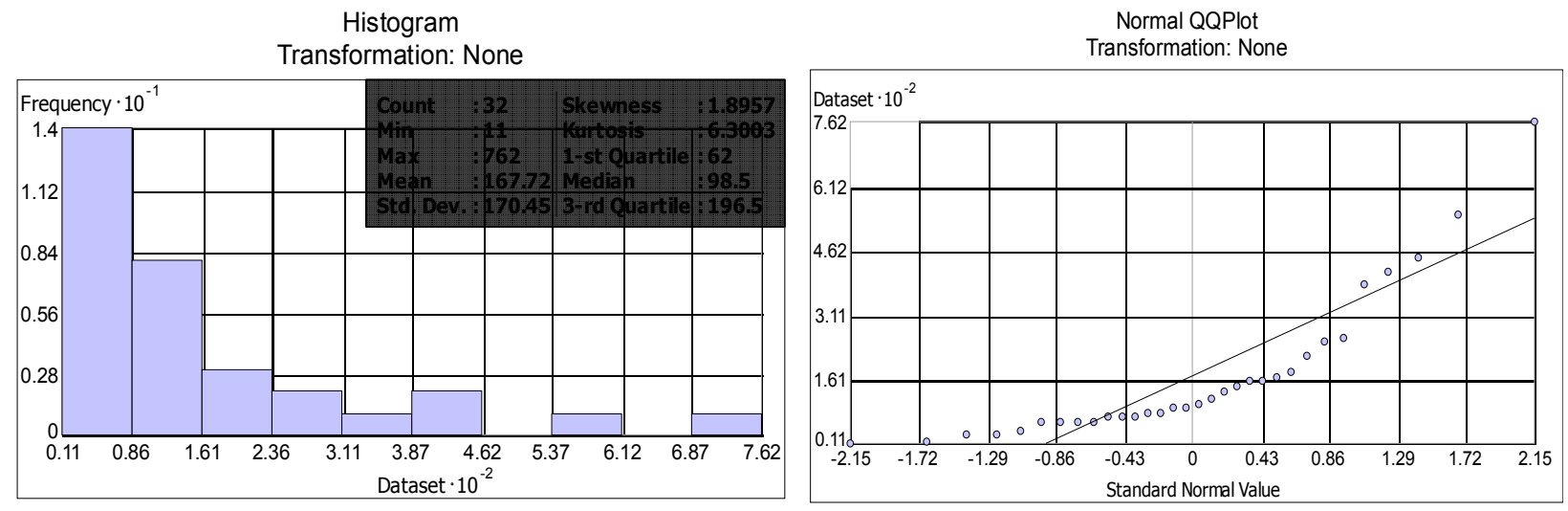

Dataset : point_2 Attribute: availabl_2

Dataset : point_2 Attribute: availabl_2

Original data of the available soil $\mathrm{K}$ in site $\mathrm{D}$ as an example of deviated data from normal distribution.

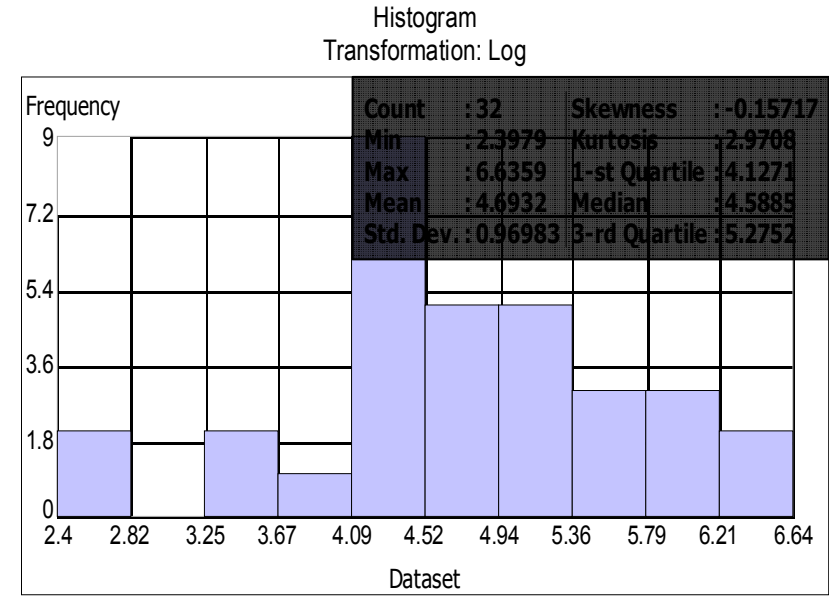

Dataset : point_2 Attribute: availabl_2

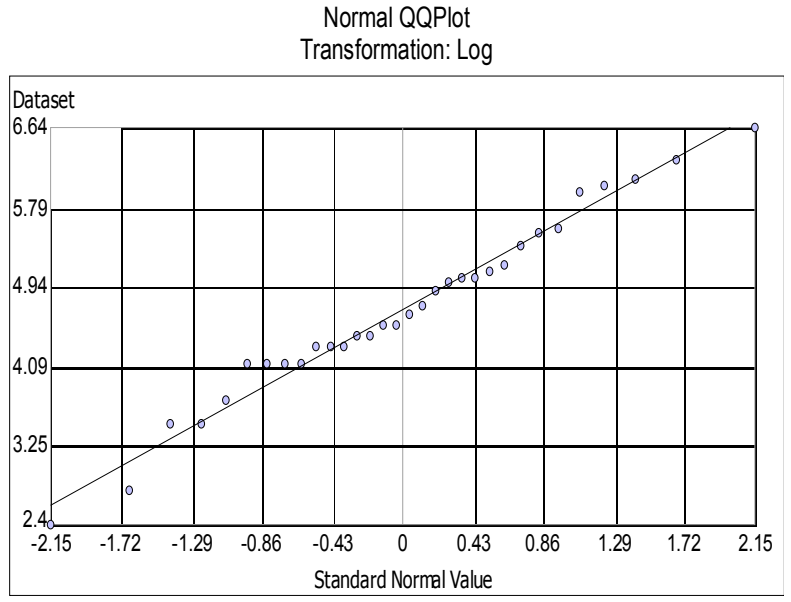

Dataset : point_2 Attribute: availabl_2

Logarithmic transformed data of the available soil $\mathrm{K}$ in site $\mathrm{D}$ after applying log-transformation.

Figure (4): Examples of histograms and QQPlots for available soil $\mathrm{P}$ and $\mathrm{K}$ data in some study sites.

\subsubsection{Semivariogram spatial dependency}

The semivariogram spatial dependency of the available soil $\mathrm{P}$ and
$\mathrm{K}$ contents of the study area is illustrated in Figure (5). The models and their parameters are also present in Table (4). Semivariograms and the 
spatial variability of available soil $\mathrm{P}$ and $\mathrm{K}$ contents and their relation to lag of the samples and semivariance were produced from geostatistical software, ArcGIS, version (10.2.2). There were three variables which used in calculating the spatial dependency. They were nugget, sill and range (a). Nugget variance represents the experimental error and field variation within the minimum sampling spacing and inherent variability (Cambardella et al., 1994). In the cur- rent study, nugget values were the lowest and positive for $\mathrm{P}$ and $\mathrm{K}$ suggesting a positive nugget effect that may be due to the sampling error or a random and inherent variability of the available soil $\mathrm{P}$ and $\mathrm{K}$ contents (Wang et al., 2009). Sill values represent the total spatial variation (Liu et al., 2013), in all study sites, and ranged from 0.174 to 85.73 and from 0.106 to1810365 for the soil available $\mathrm{P}$ and $\mathrm{K}$ contents, respectively.

Table 4. Fitted models and their parameters for the semivariograms of available soil $P$ and $K$ contents.

\begin{tabular}{|l|l|l|c|c|c|c|c|}
\hline \multirow{2}{*}{ Nutrient } & \multirow{2}{*}{ Site } & \multirow{2}{*}{ Model } & \multicolumn{5}{|c|}{ Prediction Error } \\
\cline { 4 - 8 } & & & Nugget $\left(\mathbf{C}_{\mathbf{0}}\right)$ & Sill $\left(\mathbf{C}_{\mathbf{0}}+\mathbf{C}\right)$ & Nugget / Sill & $\begin{array}{c}\text { Range } \\
(\mathbf{a})\end{array}$ & $\begin{array}{c}\text { Spatial } \\
\text { Class }\end{array}$ \\
\hline P & A & K-bessel & 0.0001 & 0.430 & 0.023 & 0.005 & S \\
\hline & B & Exponential & 0.01 & 85.73 & 0.012 & 0.006 & S \\
\hline & C & Spherical & 0.001 & 0.7998 & 0.125 & 0.004 & S \\
\hline & D & K-bessel & 0.0001 & 0.174 & 0.0574 & 0.006 & S \\
\hline K & & & & & & & \\
\hline & A & Spherical & 0.001 & 0.621 & 0.161 & 0.001 & S \\
\hline & B & Rational Quadratic & 9600 & 1810365 & 0.530 & 0.007 & S \\
\hline & C & Rational Quadratic & 0.0001 & 0.106 & 0.094 & 0.003 & S \\
\hline & D & Pentaspherical & 0.00002 & 1.095 & 0.0018 & 0.007 & S \\
\hline
\end{tabular}

$\mathrm{S}=$ Strong spatial dependency, Nugget/Sill $=$ Nugget/Sill $* 100=$ Spatial class ratio, Range $(\mathrm{a})=$ spatial rang

The spatial dependency (nugget/sill ratio, expressed as percentage) that is similar to those presented by Cambardella et al.(1994) was adopted to define the distinctive classes of spatial dependence. A variable is considered to have a strong spatial dependency if the nugget/sill ratio is less than 25 percent, a moderate spatial dependency if the ratio is between 25 - 75 percent and a weak spatial dependency if the nugget/sill ratio is greater than 75 percent. Cambardella et al. (1994) also reported that a strong spatial dependency of soil characteristics can be attributed to the intrinsic factors (soil formation factors such as parent materials), and a weak spatial dependency can be attributed to the extrinsic factors (soil management practices such as fertilization).

In this study, the nugget/sill ratio was less than $25 \%$ for the available $\mathrm{P}$ and $\mathrm{K}$ contents in all sites, which indicate a strong spatial dependency for the soil available $\mathrm{P}$ and $\mathrm{K}$ contents. Strongly spatially dependent properties may be controlled by an intrinsic variation in soil characteristics such as the texture and the mineralogy (Cambardella et al., 1994). The stronger the spatial correlation, the more accurate is the soil property map that could be obtained using kriging. K-bessel, exponential 
and spherical models were best performed for the available soil $\mathrm{P}$ content while spherical, pentaspherical

(a)
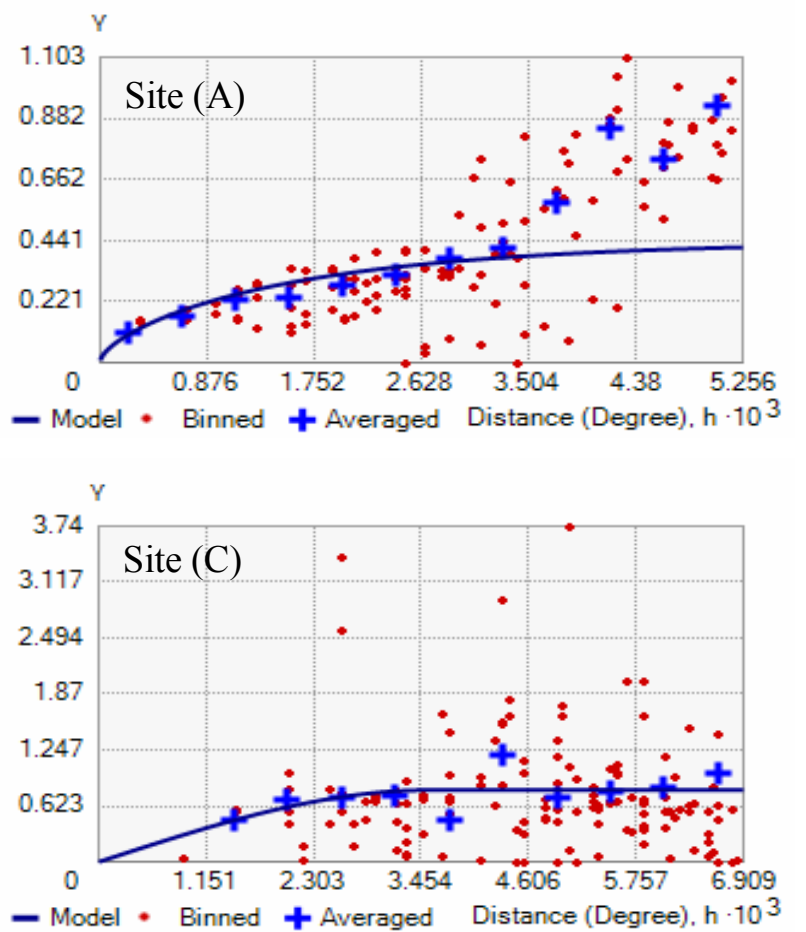

(b)
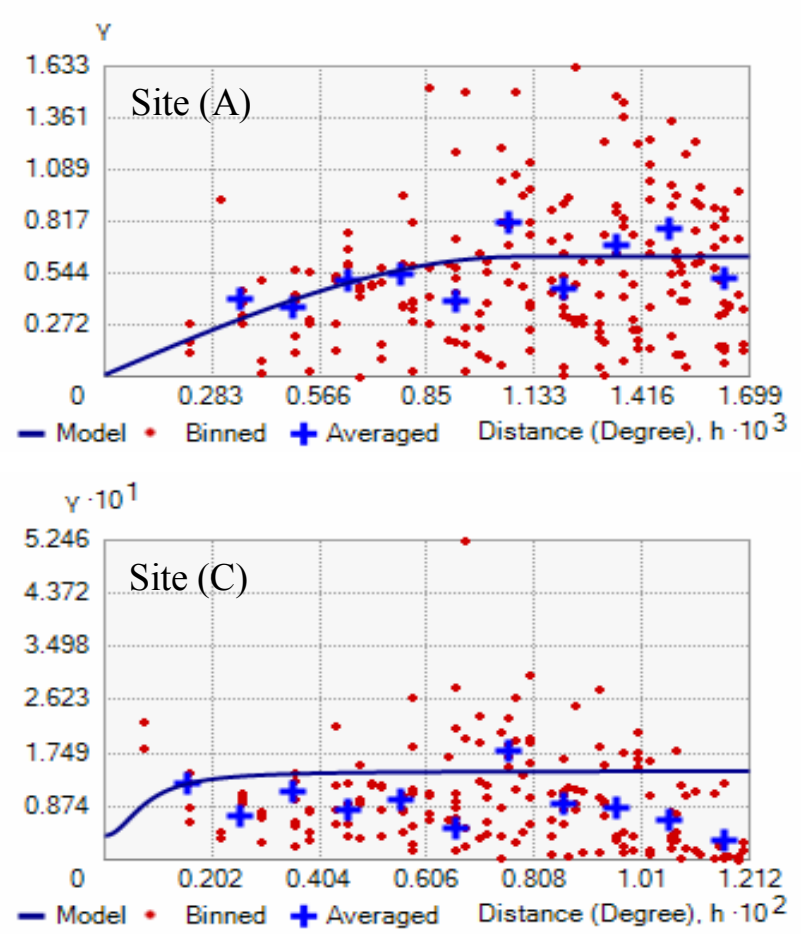

and rational quadratic models were the best for the available soil $\mathrm{K}$ content (Table 4).
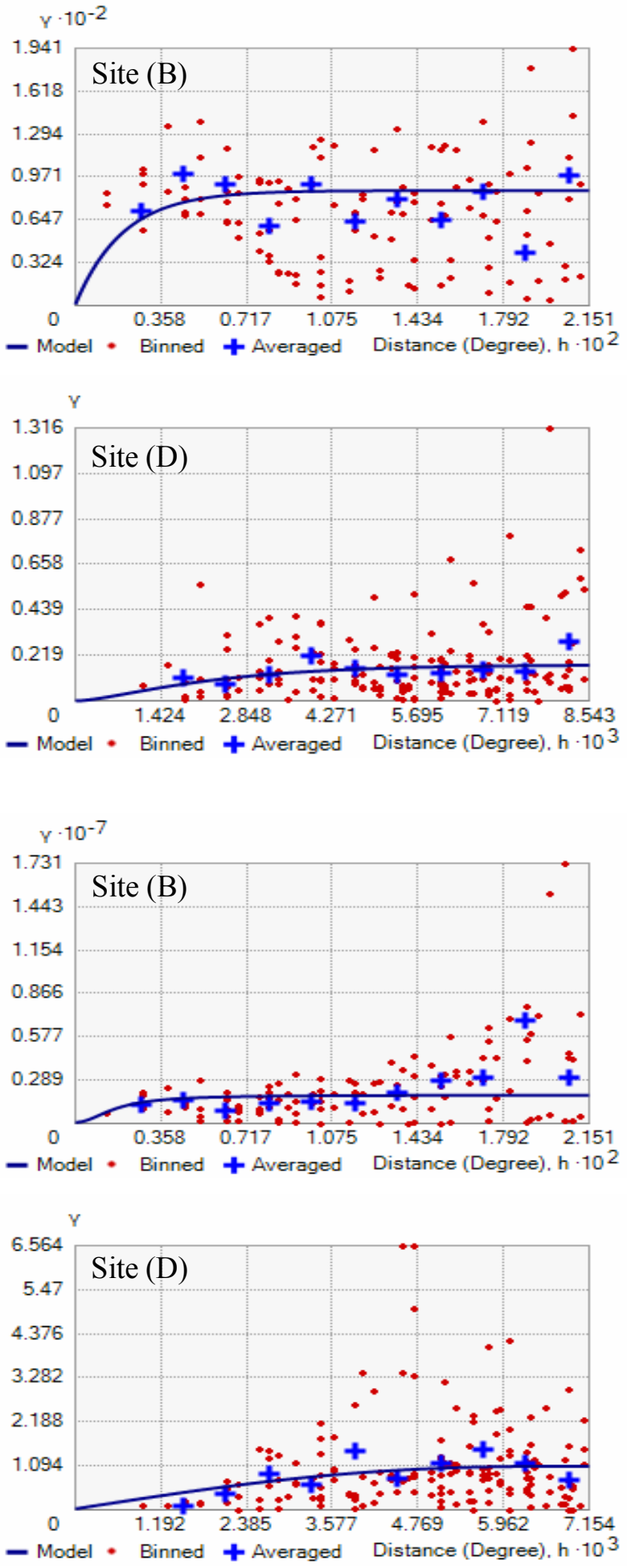

Figure (5): Semivariograms of the available soil P (a) and K (b) contents of the study sites. 


\subsubsection{Cross-validation and} comparison of interpolation model performance

The current study used the ordinary kriging (OK) technique to produce the patterns of available soil $\mathrm{P}$ and $\mathrm{K}$ distributions. Prediction performances are assessed by the crossvalidation, which examines the accuracy of the generated surfaces. After applying different models (eleven models) for the available soil $\mathrm{P}$ and $\mathrm{K}$ that were examined in this study, the error was calculated using the crossvalidation technique to identify the most accurate predictions such as the mean standardized error (MSE) and the root mean square standardized error (RMSS). The lowest mean standardized error values close to zero and the root mean square standardized values close to one indicate that kriging predictions values are closer to the measured values. The models that gave the best results were chosen.

Prediction error values for both investigated available soil $\mathrm{P}$ and $\mathrm{K}$ are present in Table (5). The root mean square standardized error (RMSS) values for the chosen models varied from 0.8618 to 1.1305 for the available soil $\mathrm{P}$ and from1.0434 to1.3108 for the available soil $\mathrm{K}$ (close to one). The mean standardized error (MSE) values for available soil $\mathrm{P}$ and $\mathrm{K}$ data ranged from -0.0784 to 0.0020 and from -0.1230 to -0.0152 , respectively, which were close to zero, indicating that the ordinary kriging $(\mathrm{OK})$ produced relatively unbiased values for spatial interpolation. These findings proved that the chosen models were the best fitted semivariogram models to map spatial distribution of the available soil $\mathrm{P}$ and $\mathrm{K}$ in this study.

Table 5. The prediction errors of the available soil $P$ and $K$ of the study sites.

\begin{tabular}{|c|c|c|c|c|c|c|c|c|}
\hline \multirow{2}{*}{ Property } & \multirow{2}{*}{\begin{tabular}{c} 
e \\
\cline { 4 - 9 }
\end{tabular}} & \multicolumn{7}{|c|}{ Prediction Errors } \\
\hline Available P & A & 0.201 & 9.549 & 8.579 & -0.0060 & 1.0384 & 0.30 & 3.24 \\
\hline & $\mathrm{B}$ & -0.030 & 9.930 & 8.884 & -0.0026 & 1.1305 & 0.80 & 3.76 \\
\hline & $\mathrm{C}$ & 0.358 & 4.891 & 7.639 & -0.0784 & 0.8618 & -0.32 & 3.21 \\
\hline & $\mathrm{D}$ & 0.231 & 5.577 & 5.871 & -0.0020 & 1.0002 & -1.03 & 4.62 \\
\hline Available K & $\mathrm{A}$ & 22.930 & 284.862 & 308.245 & -0.1199 & 1.0434 & -0.24 & 2.88 \\
\hline & $\mathrm{B}$ & -24.597 & 1352.744 & 1270.216 & -0.0152 & 1.0471 & 1.14 & 4.57 \\
\hline & $\mathrm{C}$ & -8.534 & 310.116 & 246.558 & -0.1136 & 1.3108 & 0.44 & 7.50 \\
\hline & $\mathrm{D}$ & -0.049 & 163.785 & 202.932 & -0.1230 & 1.0840 & -0.16 & 2.97 \\
\hline
\end{tabular}

RMS = Root Mean Square; ASE = Average Standard Error; MS = Mean Standardized and RMSS $=$ Root Mean Square Standardized.

3.3.4 Spatial distribution mapping of soil available $P$ and $K$ contents

Maps of the spatial distribution were produced using previously the chosen models with applying ArcGIS. Figures (6) and (7) illustrate the spatial distribution maps of the available soil $P$ and $K$ in the studied sites of the study area. With respect to the spatial distributions of the available soil $\mathrm{P}$, the maps showed that the soils of all investigated sites have the levels of $10-25 \mathrm{mg} / \mathrm{kg}$ except 
these of site $\mathrm{C}$ which had available soil P levels of less than $10 \mathrm{mg} / \mathrm{kg}$. The highest levels available $\mathrm{P}$ were found in the eastern part of site $A$, the northern third part of site B and few spots in the southern half part of site D. However, the lowest levels occurred in separate spots in the western half part of site A and few separate spots in the southern half part of sites $\mathrm{B}$ and $\mathrm{D}$ (Figure 6).

On the other hand, the spatial distribution maps of the available soil $\mathrm{K}$ revealed that the dominant level in the soils of all sites was $250-800$ $\mathrm{mg} / \mathrm{kg}$, except these of site $\mathrm{D}$ that had less than $150 \mathrm{mg} / \mathrm{kg}$ as a predominant level. Also, maps of the spatial distributions of the available soil $\mathrm{K}$ showed highest levels of available $\mathrm{K}$ occurred in separate spots in site A, in the southern third part of site B, in the western north and eastern south part for site $\mathrm{C}$ and in western north part of site D (Figure 7).

Based on the spatial distribution of soil $\mathrm{P}$ and $\mathrm{K}$ availability, specific site management can be planned and considered to be applied for each site of this study area. Therefore, the maps of the spatial distributions of available soil $\mathrm{P}$ and $\mathrm{K}$ can give realistic information about nutrient status. Also, these maps can facilitate the estimation of the fertilization policies of $\mathrm{P}$ and $\mathrm{K}$ for different crops in these investigated sites.
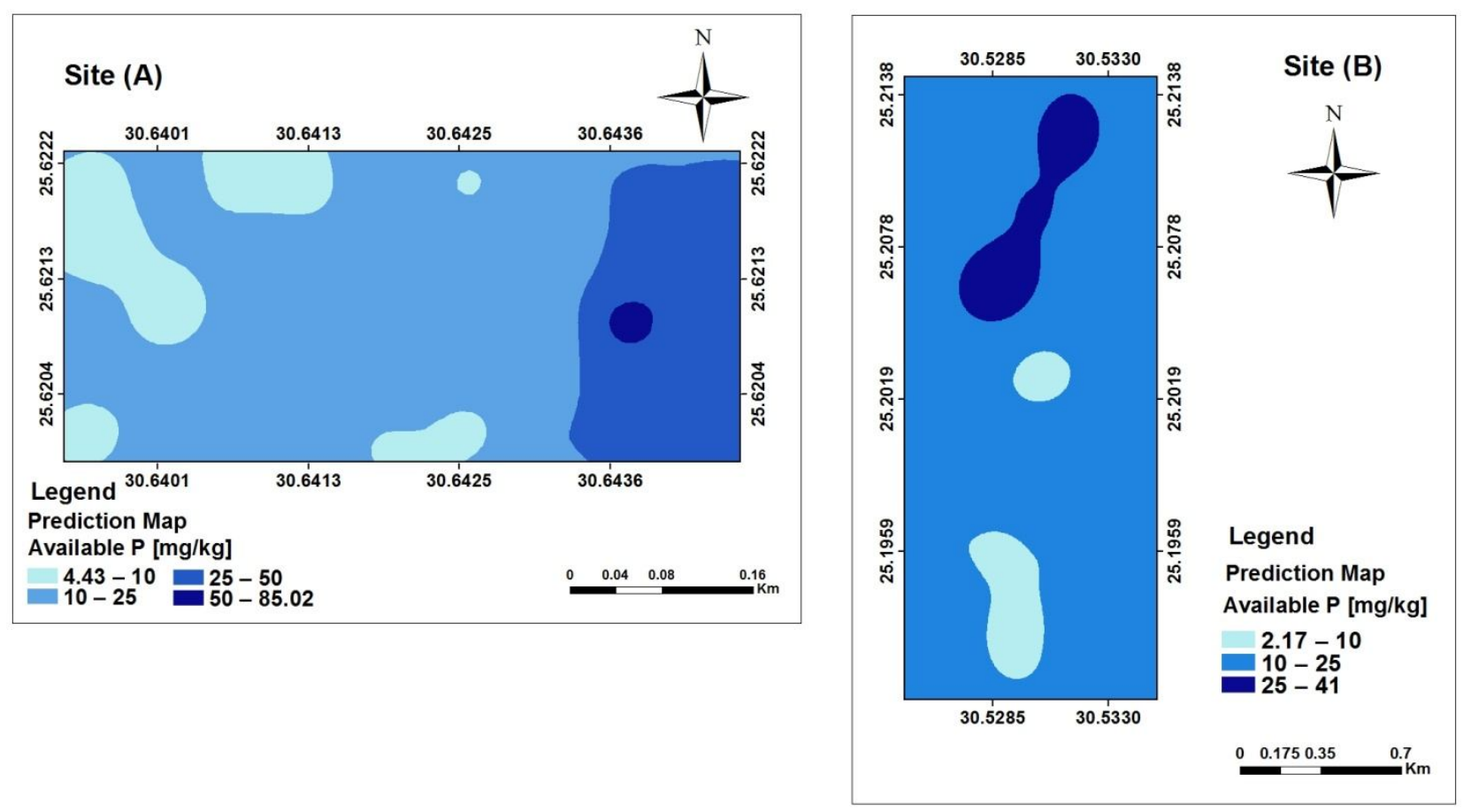

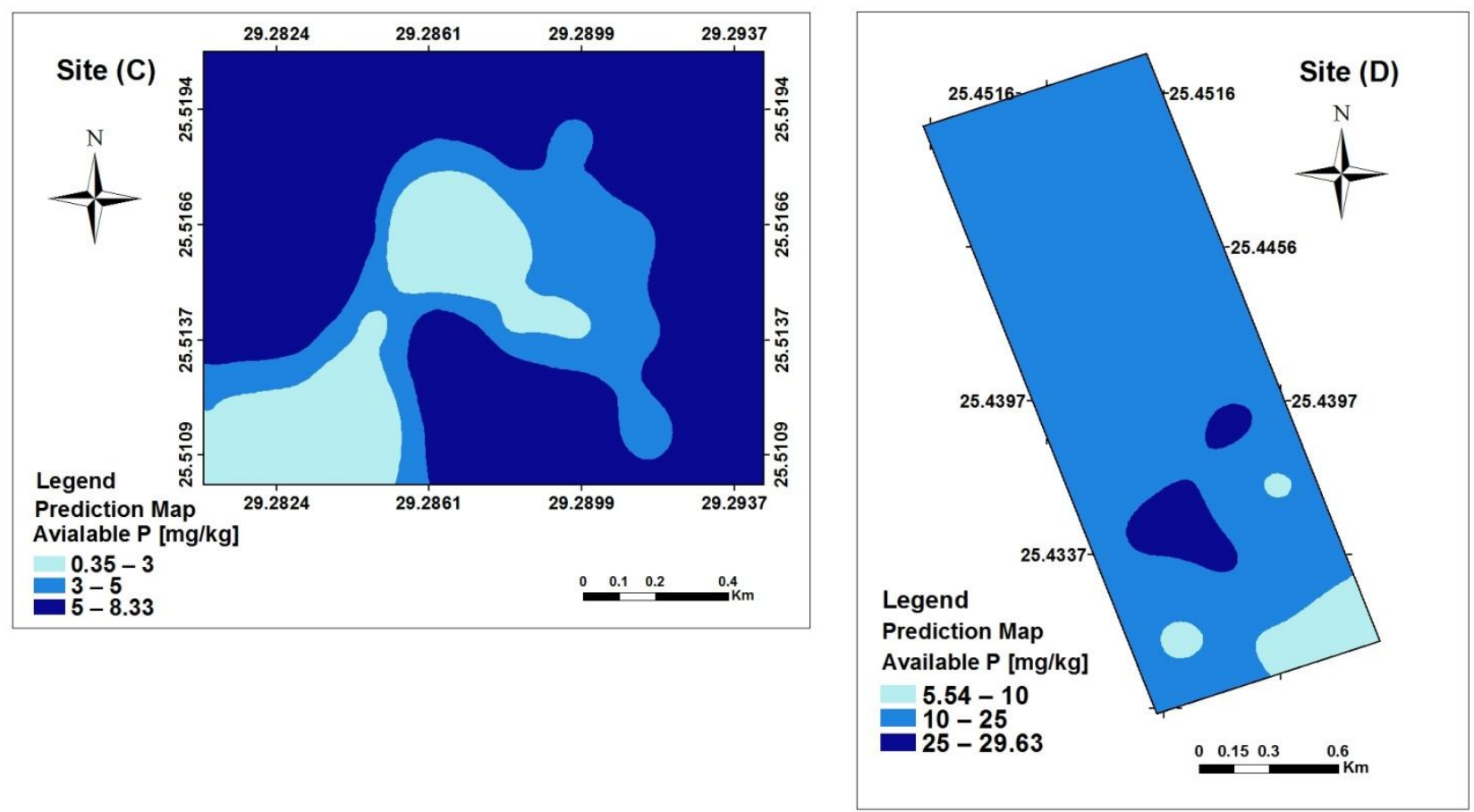

Figure (6): Spatial distribution maps of the available soil $\mathrm{P}$ in the study sites.

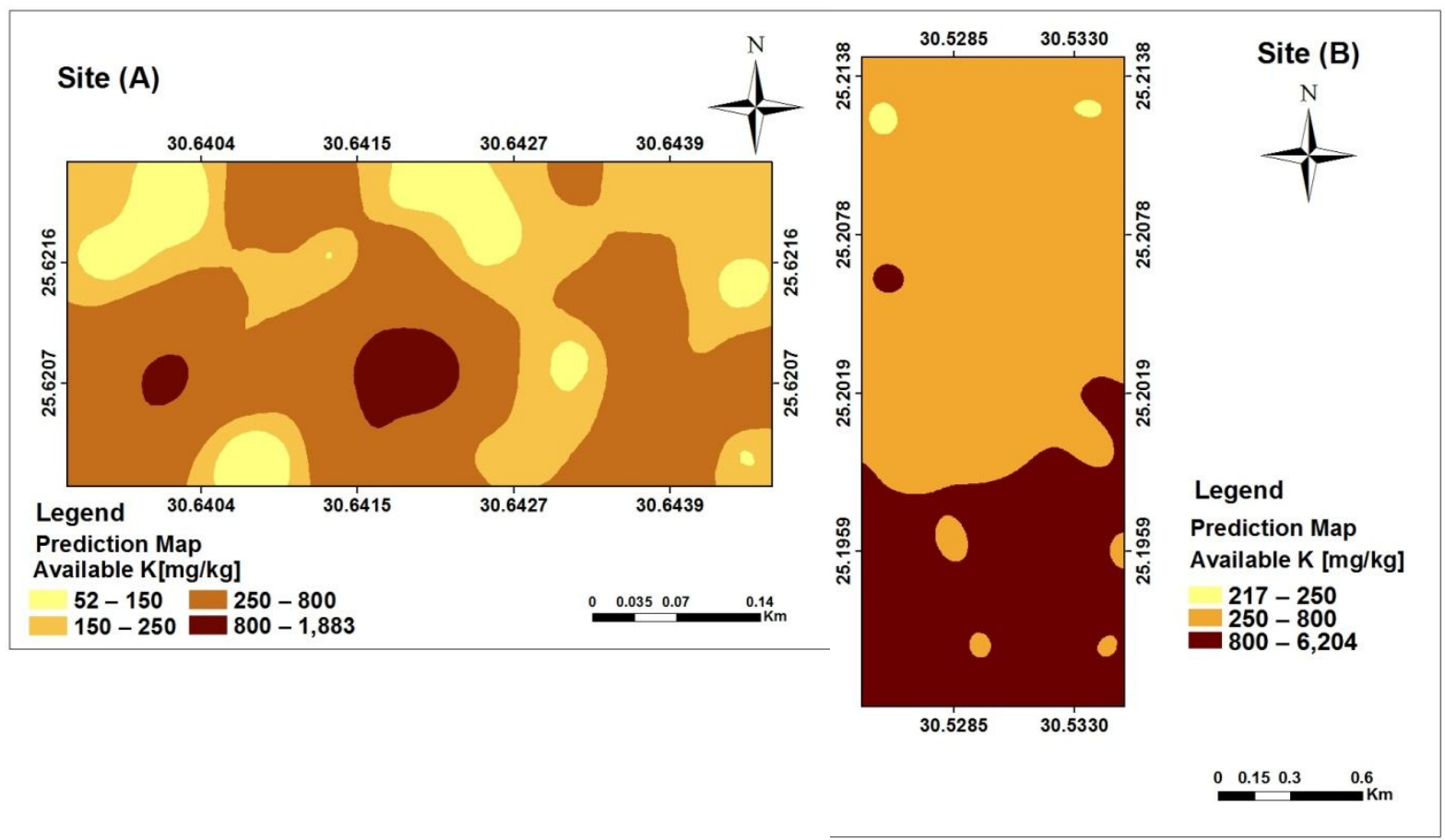



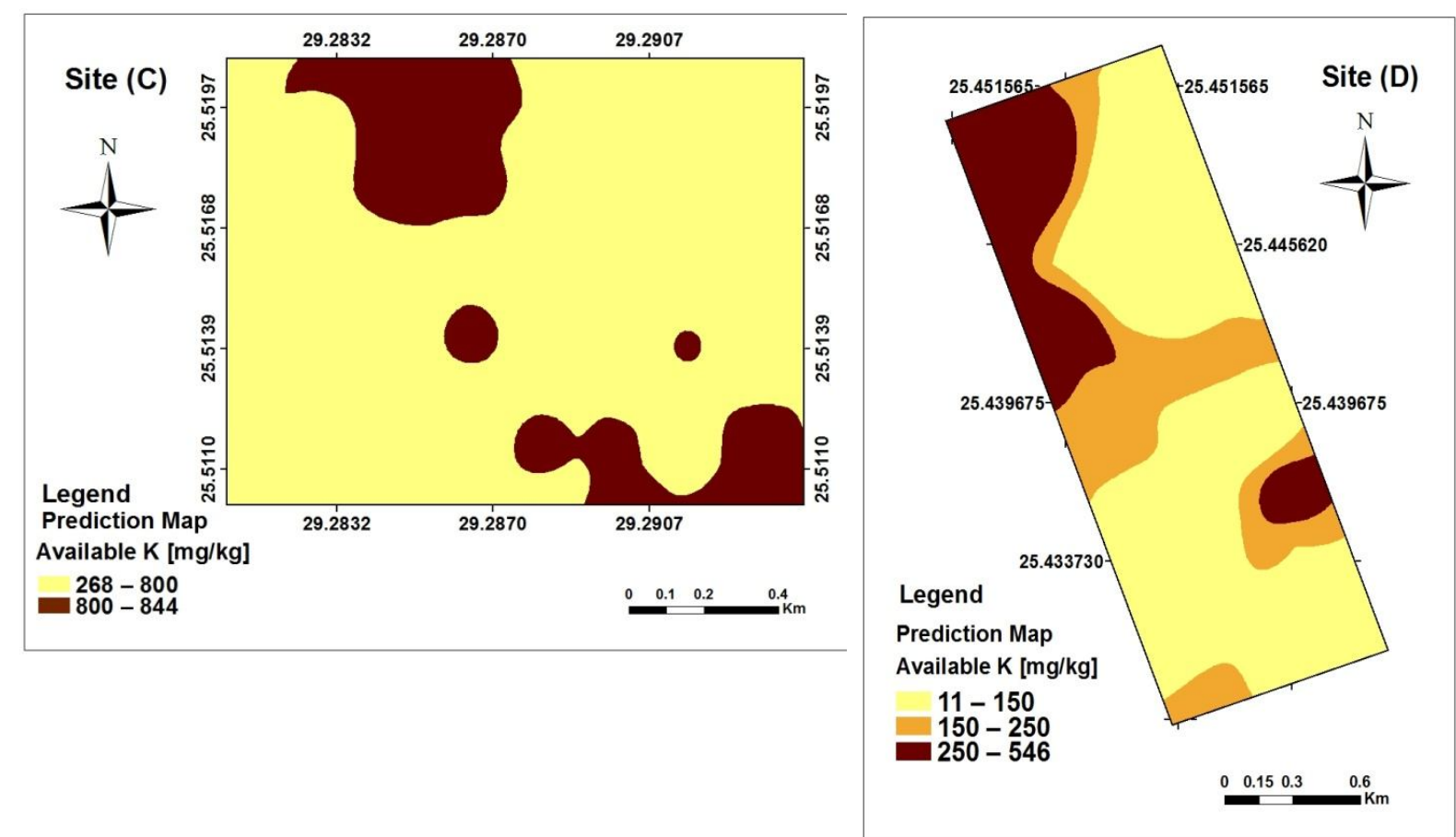

Figure (7): Spatial distribution maps of the available soil K in the study sites.

\section{Conclusion}

The current study showed that the studied coarse-texture soils have a moderate level of available $\mathrm{P}$ in all sites, except site $\mathrm{C}$ which had a low level. Also, these soils have high and very high levels of available $\mathrm{K}$ in all sites. The available soil $\mathrm{K}$ content of the studied samples in all sites was higher than the available soil P.

The spatial interpolation of the available soil $P$ and $K$ contents in the surface soil samples $(0-25 \mathrm{~cm})$ of the study area showed that k-bessel, exponential, spherical, pentaspherical and rational quadratic models were the best performed in describing the spatial dependency of both nutrients. The cross-validation demonstrated that the ordinary kriging technique was the best in describing the spatial interpolation of these nutrients. Both available soil $\mathrm{P}$ and $\mathrm{K}$ stocks showed a strong spatial dependence, indicat- ing that both available soil $\mathrm{P}$ and $\mathrm{K}$ contents were mainly controlled by intrinsic factors. Geostatistical analysis integrated with GIS provided an opportunity to assess the variability in the distribution of these nutrients.

This study also revealed that using the produced spatial distributions maps for the soil $\mathrm{P}$ and $\mathrm{K}$ availability, site specific management can be planned and considered to be applied for this study area. These maps can facilitate and help in make decisions for choosing appropriate fertilization policies for soils as well as to avoid adding too high fertilizer levels to get aclean environment. On the other hand, the study proved that statistics and geostatistics analyses are powerful tools to assess, understand and map the spatial variability of the available soil phosphorus and potassium. 


\section{Reference:}

Atreya, K.S., R.M. Sharma, N.P. Bajracharya, (2008). Developing a sustainable agro-system for central Nepal using reduced tillage and straw mulching. J Environ Manag 88:547-555.

Barton, A.P., M.A. Fullen, D.J. Mitchell, (2004). Effects of soil conservation measures on erosion rates and crop productivity on subtropical Ultisols in Yunnan province, China. Agric. Ecosystem Environ 104:343-357.

Brady, N.C., R.R. Weil, (2000). Nature and properties of soils. Macmillan publishing company, New York, pp. 392-393.

Cambardella, C.A., T.B. Moorman, J.M. Novak, T.B. Parkin, D.L. Karlen, R.F. Turco and A.E. Konopka, (1994). Field-scale variability of soil properties in central iowa soils. Soil Sci. Soc. Am. J., 58, 1501-1511.

Elrashidi, M.A., L.T. West, N. Persaud, (2012). Phosphorus loss and forms in runoff from watersheds in the Great Plains. Soil Sci 177:638649.

Fang, X., Z. Xue, B. Li and S. An, (2012). Soil organic carbon distribution in relation to land use and its storage in a small watershed of the loess plateau, china. Catena. 88, 6-13.

$\mathrm{Fu}$ W.J., K.L. Zhao, H. Tunney, and C.S. Zhang, (2013). Using GIS and geostatistics to optimize soil phosphorus and magnesium sampling in temperate grassland. Soil Sci 178:240-247.

Goovaerts, P., (1999). Geostatistical in soil science: state of the art and perspectives. Geoderma 89, 1-5-45.

Horneck, D.A., D.M. Sullivan, J.S. Owen, and J.M. Hart, (2011). Soil Test Interpretation Guide. Oregon
State University, EC 1478-E, http://extension.oregonstate.edu/ca talog/.

Huang CY (2000). Soil Science. China Agriculture Press, Beijing, pp. 20301.

Isaaks, E.H. and R.M. Srivastava, (1989). An introduction to applied geostatistics. New York: Oxford University Press.

Jackson, M.L. (1973). Soil chemical analysis. Prentice-Hall, Inc., Engel wood Cliffs, NJ, and USA.

Johnston, K., J.M.V. Hoef, K. Krivoruchko, and N. Lucas, (2001). Using ArcGIS TM geostatistical analyst. ESRI. $380 \mathrm{New}$ York Street. Redlands, CA 923738100, USA.

Journel, A.G. and Ch. J. Huijbregts, (1978). "Mining Geostatistics". New Yourk, Academic Press.

Krige, D.A. (1951). Statistical approach to some basic mine valuation problems on the Witwatersrand. J.Chem. Metall. Mining Soc. S. Afr. 52, 119-139.

Li, Y., S. Niu, and G. Yu, (2016). Aggravated phosphorus limitation on biomass production under increasing nitrogen loading: A metaanalysis. Glob. Chang. Biol. 22, 934-943.

Lin, J., X. Shi, X. Lu, D. Yu, H. Wang, Y. Zhao and W. Sun, (2009). Storage and spatial variation of phosphorus in paddy soils of china. Pedosphere. 19, 790-798.

Liu, Z., M.A. Shao, Y. Wang, (2013). Spatial patterns of soil total nitrogen and soil total phosphorusacross the entire loess plateau region of china. Geoderma. 197-198, 6778.

Marklein, A.R. and B.Z. Houlton, (2012). Nitrogen inputs accelerate phosphorus cycling rates across a wide variety of terrestrial ecosystems. New Phytol. 193, 696-704. 
Matheron, G. (1971). The theory of regionalized variables and its applications, Les Cahiers du Centre de Morphologie Math'ematique, no. 5, Ecole des Mines de Paris, $211 \mathrm{p}$.

Olsen, S.R., C.V. Cole, F. Watanabe, and L.A. Dean, (1954). Estimation of available phosphorus in soil by extraction with sodium bicarbonate. Cric. 989, USDA, Washington, D.C.

Page, A. L., R.H. Miller, and D. R. Keeney, (1984). Methods of Soil Analysis. Part2, Chemical and Microbiological Properties, 2ed. USA. p.p.: 815-830.

Robertson, G.P. (2008). GeoStatistics for the environmental sciences. Gamma design software, pp. 1-20.

Sauer, T.J., C.A. Cambardella, and D.W. Meek, (2006). Spatial variation of soil properties relating to vegetation changes. Plant Soil 280:1-5.

Sarangi, A., C.A. Cox, and C.A. Madramootoo, (2005). Geostatistical Methods for Prediction of Spatial Variability of Rainfall in a Mountainous Region. Transactions of ASAE, 48(3): 943-954.

Tang, G.A. and X. Yang, (2006). Experimental course of ArcGIS for spatial analysis of geography in- formation system. Science Press, Beijing.

Tripler, C., S. Kaushal, G. Likens and M. Walter, (2006). Patterns in potassium dynamics in forest ecosystems. Ecol. Lett. 9, 451-466.

Wang, Y., X. Zhang, and C. Huang, (2009). Spatial variability of soil total nitrogen and soil total phosphorus under different land uses in a small watershed on the loess plateau, china. Geoderma 150, 141149.

Wu, J., A. Norvell, D.G. Hokins, D.B. Smith, M.G. Ulmer, R.M. Welch, (2003). Improved prediction and mapping on soil copper by kriging with auxiliary data for cationexchange capacity. Soil Sci Soc. Am J 67:919-927.

Yamamoto, J.K. (2005). Comparing ordinary kriging interpolation variance and indicator kriging conditional variance for assessing uncertainties at unsampled locations, In: Application of Computers and Operations Research in the Mineral Industry - Dessureault, GanN.P. Guli, Kecojevic, \& Dwyer editors, Balkema. 
تقييم ورسم خرائط التباين المكاني لمحتوي التربة من الفسفور والبوتاسيوم الميسر في التوائ

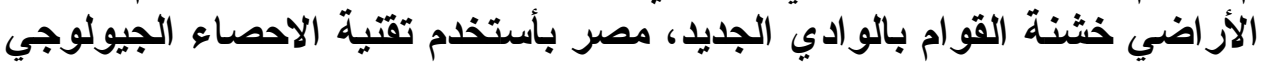

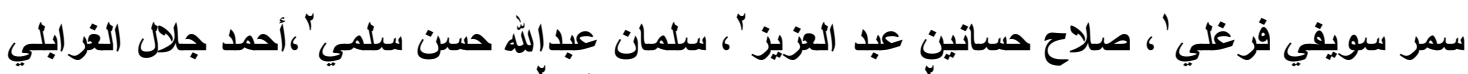

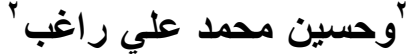

$$
\begin{aligned}
& \text { ' قسم الأر اضي و المياه - كلية الزر اعة بالو ادي الجديد - جامعة أسيوط } \\
& \text { "َّم الآر اضي و المياه - كلية الزر اعة - جامعة أسيوط }
\end{aligned}
$$

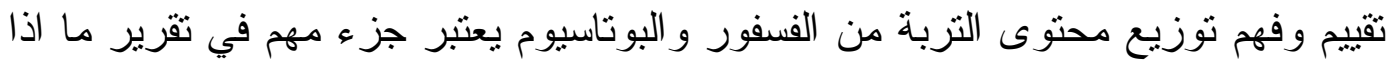

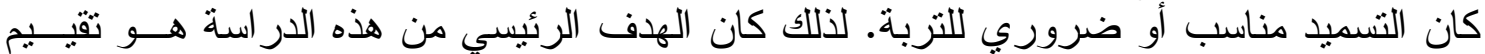

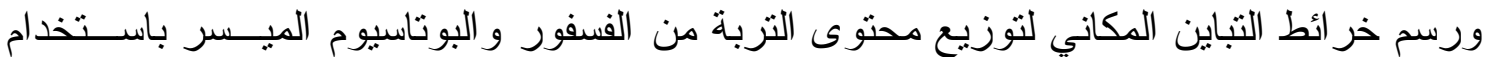

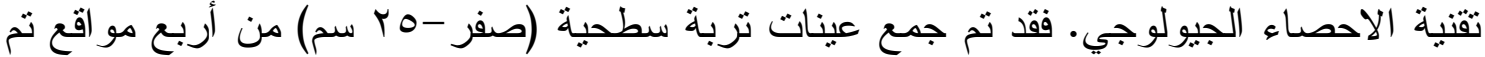

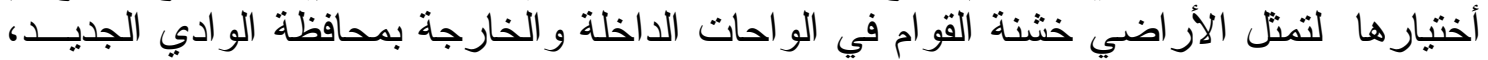

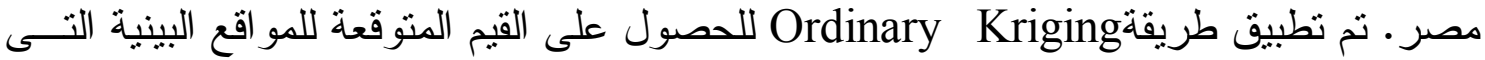

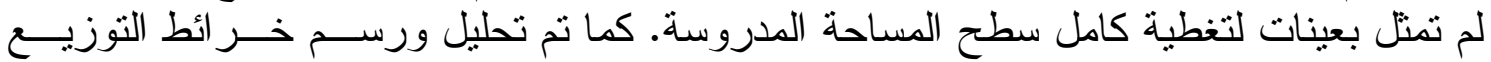

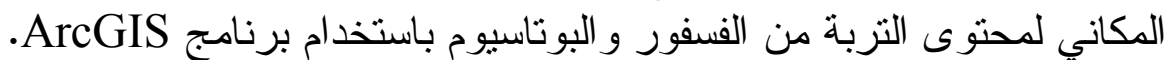

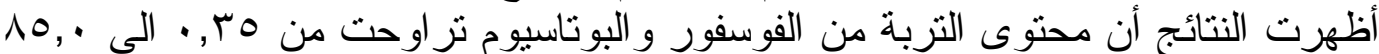

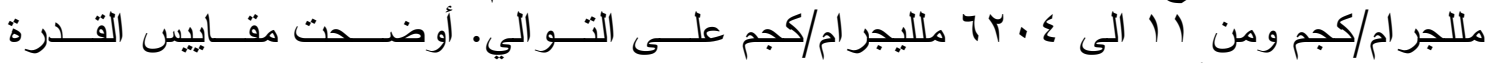

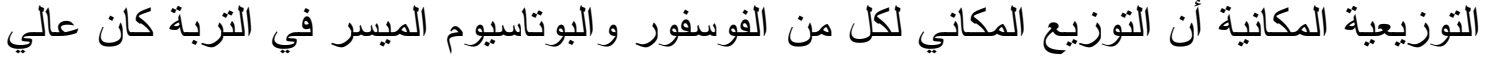

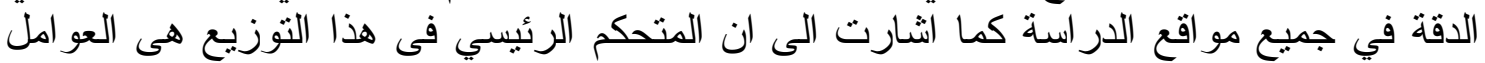

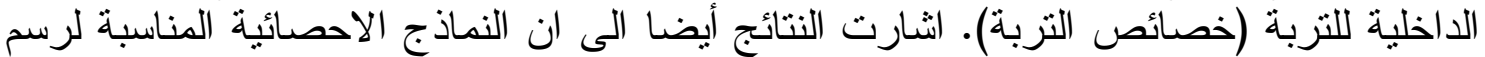

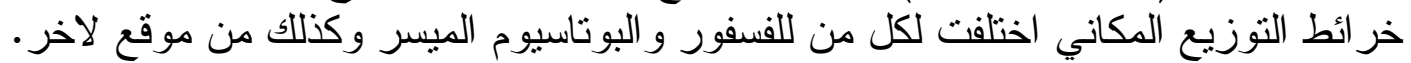

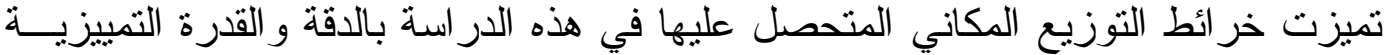

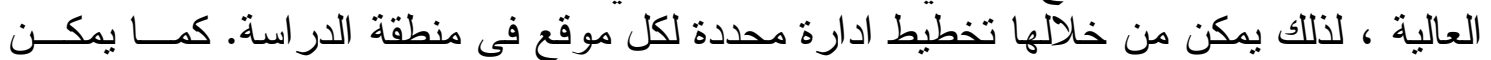

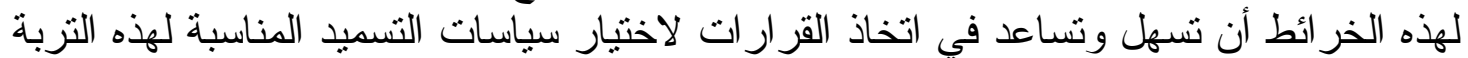

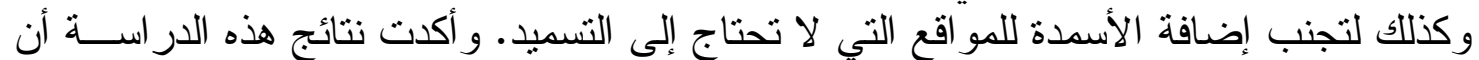

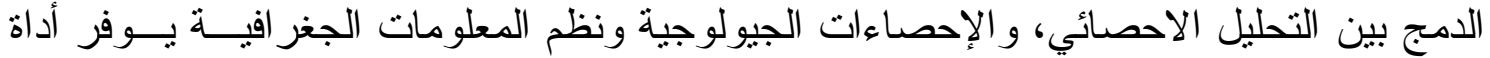

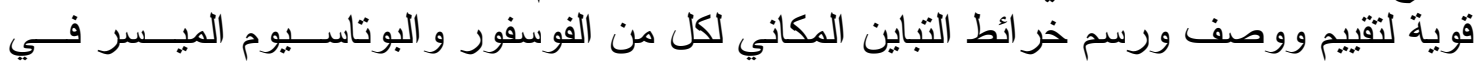

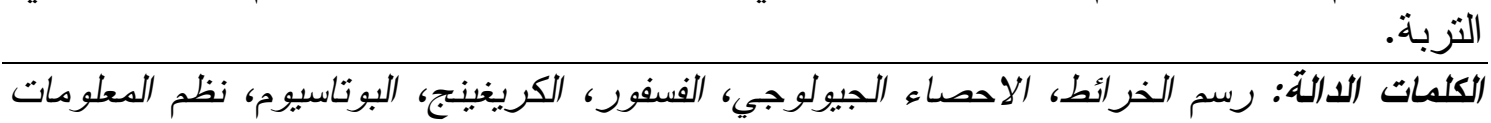

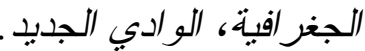

